\title{
Research on Initiation Sensitivity of Solid Explosive and Planer Initiation System
}

\author{
Nobuyuki Matsuo',*, M. Otuka², H. Hamasima³, K. \\ Hokamoto $^{4}$, S. Itoh ${ }^{5}$ \\ ${ }^{1}$ Graduate School of Science and Technology, Kumamoto University \\ ${ }^{2}$ Asahikasei Chemicals Corporation \\ ${ }^{3}$ Kumamoto Industrial Research Institute \\ ${ }^{4}$ Shock Wave and Condensed Matter Research Center, \\ Kumamoto University \\ ${ }^{5}$ Okinawa National College of Technology
}

\begin{abstract}
Firstly, recently, there are a lot of techniques being demanded for complex process, various explosive initiation method and highly accurate control of detonation are needed. In this research, the metal foil explosion using high current is focused attention on the method to obtain linear or planate initiation easily, and the main evaluation of metal foil explosion to initiate explosive was conducted. The explosion power was evaluated by observing optically the underwater shock wave generated from the metal foil explosion.

Secondly, in high energy explosive processing, there are several applications, such as shock compaction, explosive welding, food processing and explosive forming. In these explosive applications, a high sensitive explosive has been mainly used. The high sensitive explosive is so dangerous, since it can lead to explosion suddenly. So, for developing explosives, the safety is the most important thing as well as low manufacturing cost and explosive characteristics.

In this work, we have focused on the initiation sensitivity of a solid explosive and performed numerical analysis of sympathetic detonation. The numerical analysis is calculated by LS-DYNA 3D (commercial code). To understand the initiation reaction of an explosive, Lee-Tarver equation was used and impact detonation process was analyzed by ALE code. Configuration of simulation model is a quarter of circular cylinder. The donor type of explosive (SEP) was used as initiation explosive. When the donor explosive is exploded, a shock wave is generated and it propagates into PMMA, air and metallic layers in order. During passing through the layers, the shock wave is attenuated and finally, it has influence on the acceptor explosive, Comp.B. Here, we evaluate the initiation of acceptor explosive and discuss about detonation pressure, reactive rate of acceptor explosive and attenuation of impact pressure.
\end{abstract}

Keywords: Initiation sensitivity; Sympathetic detonation; Lee-Tarver model; Shock wave

\footnotetext{
*Correspondence Author: Nobuyuki Matsuo, Kumamoto University, 2-39-1 Kurokami, Kumamoto 860-8555, Japan, Telephone +81-96-342-3299, Fax +81-96-342-3293; nobuyuki@shock.smrc.kumamoto-u.ac.jp
} 


\section{INTRODUCTION}

Explosive is a material which generates high energy in a moment. And it is applied to many field of the society, such as material development, civil engineering, medical treatment and so on. Generally, electric detonator is used for initiating the explosive. The electric detonator is chambering primary explosive and base charge in a metal pipe and it has electrical ignition system, a current flow in the ED causes ignition of the explosive. However, in the case of using the $\mathrm{ED}$, there is a possibility that the accidental bombing happens because gunpowder is contained. Also, only not the plane shock wave but the shock wave spreads radially is obtained. There is a weak point like the above-mentioned. Therefore it is safer and needed the means to achieve the detonation of the explosive along the purpose.

In this paper, it is investigated on a new method of initiation explosive and the clarification of the initiation mechanism of explosive. Firstly, we focused on metal foil explosion using high current as an available method of planer initiation system. Initiation explosive used by metal foil explosion is applied in widespread use, such as a source of shock wave and light in optical observation. So we performed evaluation of metal foil explosion to initiate explosive. Explosion power is estimated for optical observation on under water shock wave of metal foil explosion. Also numerical simulation was conducted and validity with the experiment was investigated.

The clarification of the initiation mechanism of explosive is a theme because it prevents the accident due to sudden ignition explosion of the explosives beforehand actively researched in recent years. Then, the initiation sensitivity was investigated by using the numerical analysis for high safety of the explosive.

\section{METHOD OF EXPERIMENT}

\subsection{SELECTING METAL FOIL}

My laboratory is investigating the method of generating shock wave using electric power from the past. There is a report which investigated metal wire explosion in the past, and it is shown in table 1 . There is a report in the case of copper wire of the diameter $0.5 \mathrm{~mm}$ when the highest shock wave velocity generated. Table 2 shows material parameter. From this and past results, the good electric conductivity metal understood that the shock wave is strong. Therefore, we investigated about good electric conductivity metal such as cupper, aluminum, silver. Also, we used metal thickness is $0.03 \mathrm{~mm}$ to $0.05 \mathrm{~mm}$ as same cross section of past experiment.

\subsection{EXPERIMENTAL DEVICE}

The experiments were performed in a PMMA box, as illustrated in Fig. 1. The high-capacity condenser of capacity $10 \mathrm{~kJ}(12.5 \mu \mathrm{F}, 40 \mathrm{kV})$, made by Nichicon Corporation, was employed

Table 1 The Peak pressure of underwater shock wave

Diameter (mm)

\begin{tabular}{ccc}
\hline $\mathrm{Cu}$ & 0.1 & 198.4 \\
\hline & 0.3 & 256.4 \\
\hline Alumel & 0.5 & 357.3 \\
\hline SUS304 & 0.5 & 328.3 \\
\hline Nichrome & 0.5 & 303.5 \\
\hline
\end{tabular}


Table .2 Material property

\begin{tabular}{cccccc} 
& $\begin{array}{c}\text { Rate of electric } \\
\text { resistance } \\
\left(\times \mathbf{1 0}^{\mathbf{6}} / \mathbf{\Lambda} \cdot \mathbf{m}\right)\end{array}$ & $\begin{array}{c}\text { Density } \\
\left(\mathbf{g} / \mathbf{c m}^{\mathbf{3}}\right)\end{array}$ & $\begin{array}{c}\text { Specific } \\
\text { heat } \\
\left(\mathbf{J} / \mathbf{K g} \cdot{ }^{\circ} \mathbf{C}\right)\end{array}$ & $\begin{array}{c}\text { Heat } \\
\text { conductivity } \\
(\mathbf{W} / \mathbf{m} \cdot \mathbf{k})\end{array}$ & $\begin{array}{c}\text { Melting } \\
\text { point } \\
{ }^{\circ} \mathbf{C}\end{array}$ \\
\hline Nichrome & 0.92 & 8.52 & 461 & 17 & 1400 \\
\hline Alumel & 3.6 & 8.15 & 544 & 29.7 & 1455 \\
\hline SUS304 & 1.41 & 7.93 & 460 & 26 & 1420 \\
\hline Aluminum & 37.7 & 2.7 & 900 & 237 & 660 \\
\hline Cupper & 59.6 & 8.9 & 419 & 380 & 1083 \\
\hline Silver & 63 & 10.49 & 232 & 420 & 962 \\
\hline
\end{tabular}

for this experiment. In the present work, the experiments were performed at voltages of 40 $\mathrm{kV}$. Change of current with time was measured using a Rogowski coil attached with cables and captured by digital oscilloscope. After attaching the copper foil to the electrodes, water was placed in the PMMA box fully. When high current is loaded to the copper foil in this state, the foil is rapidly heated and changes to plasma state. After changing to plasma state, the underwater shock wave was generated. Optical observation of the underwater shock wave was performed by the shadowgraph method using high-speed video camera HPV-1 made by Shimazu corporation. The shadow graph method is used to make the shock wave and the wave phenomenon visible by the one that projects the shadow of light by the density change of the medium directly to the camera.

\subsection{METHOD OF CURRENT MEASUREMENT}

Rogowski Current Transducer "CWT600" (Made of PEM [0.05 mV/A]) was employed. Fig. 2 shows condition of installation. The Rogowski coil was set up on high voltage cable between switch and electrodes.

\subsection{METHOD OF VOLTAGE MEASUREMENT}

High Voltage Probe "PPE 20kV" (Made of LeCroy [1/1000]) was employed. Fig. 3 shows condition of installation. The probe was connected to the terminal of capacitor.
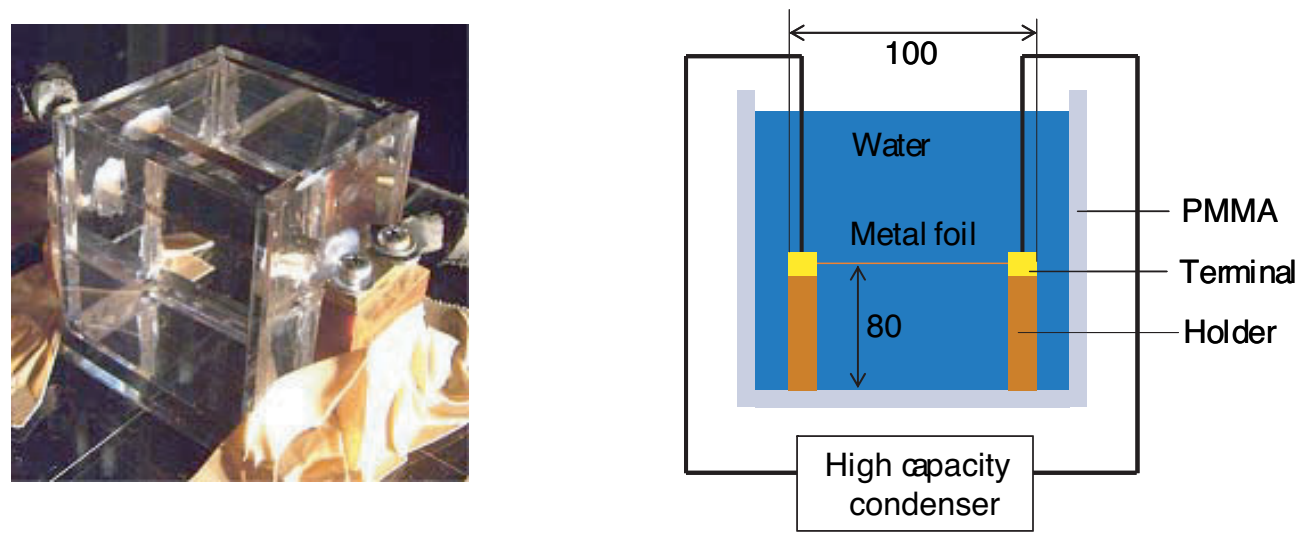

Figure 1 Experimental setup and photograph 

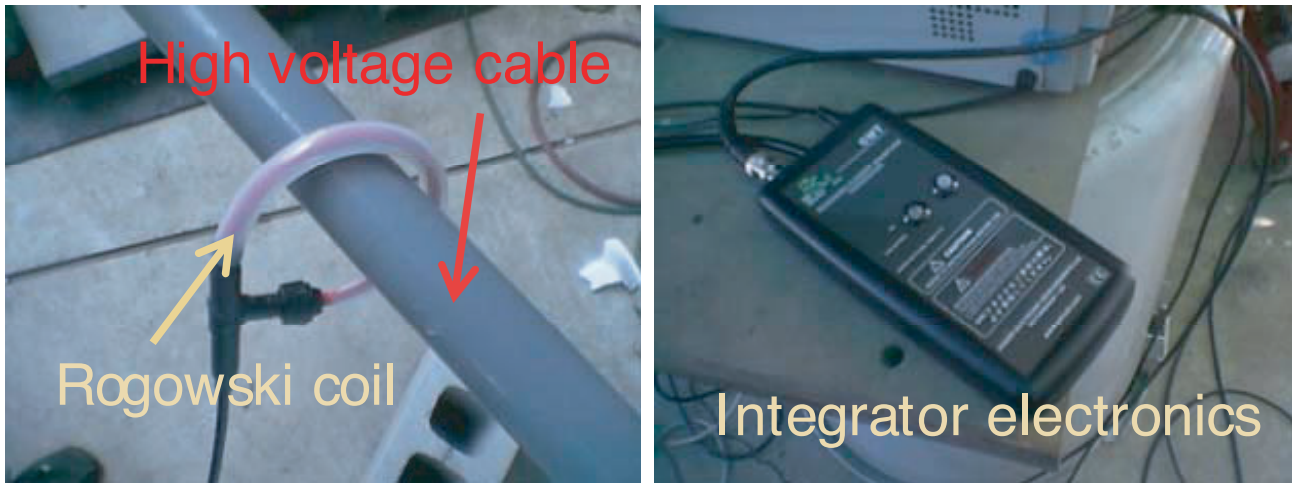

Figure 2 Condition of installation of Rogowski Current Transducer

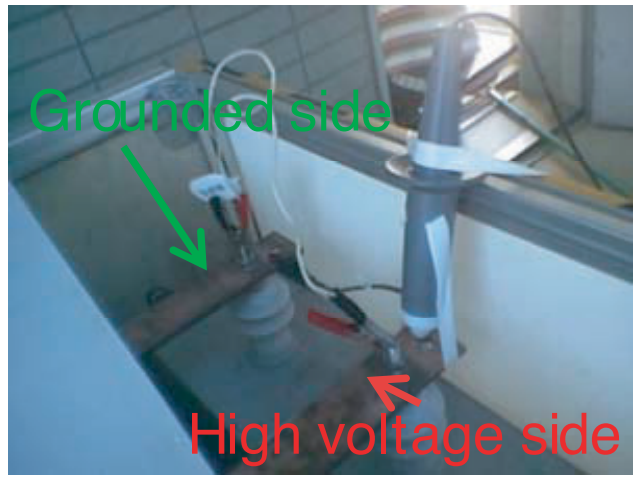

Figure 3 Condition of installation of High Voltage Probe

\subsection{NUMERICAL SIMULATION OF METAL FOIL EXPLOSION}

Also, we performed numerical analysis using LS-DYNA. LS-DYNA is a commercial finite element code supplied by Livermore Software Technology Corporation(LSTC). Model of numerical analysis is shown on Figure 4. The pressure calculation of water and copper is calculated by Mie-Grüneisen equation of state. The Johnson-Cook plasticity model is used to the high distortion speed in metal material, such as copper.

\subsection{NUMERICAL SIMULATION OF INITIATION SENSITIVITY}

The numerical analysis is calculated by LS-DYNA 3D (commercial code). To understand the initiation reaction of an explosive, Lee-Tarver equation was used and impact detonation process was analyzed by ALE code. Configuration of simulation model is a quarter of circular cylinder. This model shows Fig. 5. The donor type of explosive (SEP) was used as initiation explosive. When the donor explosive is exploded, a shock wave is generated and it propagates into PMMA. During passing through the PMMA layers, the shock wave is attenuated and finally, it has influence on the acceptor explosive, Comp. B. Here, we evaluate the initiation of acceptor explosive and discuss about detonation pressure, reactive rate of acceptor explosive and attenuation of impact pressure. 


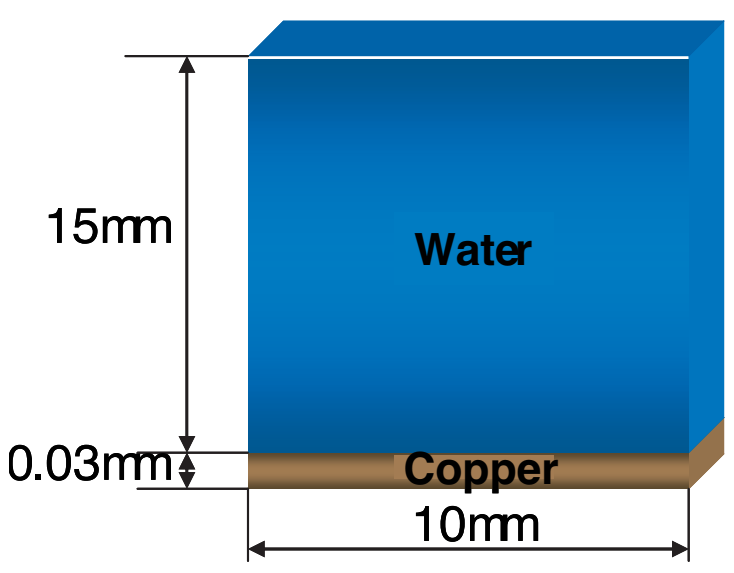

Code

LS-DYNA

Calculation method

Lagragian

Equation of state

Copper: Grüneisen

Water: Grüneisen

Mesh size

Copper : $0.01 \times 1.0 \mathrm{~mm}$

Water : $0.3 \times 1.0 \mathrm{~mm}$

Figure 4 The model of numerical analysis

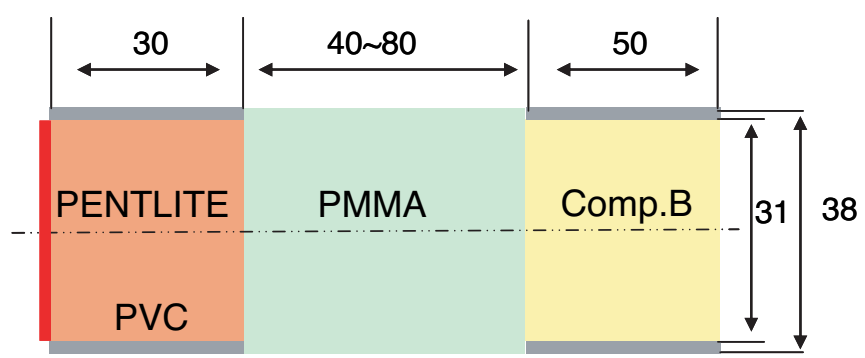

\section{Initiation}

Figure 5 Illustration of numerical analysis model for initiation test

\section{EXPERIMENTAL RESULT \& CONSIDERATION}

\subsection{MEASUREMENT RESULT}

\subsubsection{Optical observation of metal foil explosion}

Optical observation of the underwater shock wave was performed by the shadowgraph method using high-speed video camera HPV-1. The flaming photograph obtained by optical observation is shown in Fig. 6 . These are some framing photographs which I took from $0 \mu \mathrm{s}$ to $15 \mu \mathrm{s}$. It was confirmed that the shock wave was linear. And it was cleared underwater shock wave velocity and detonation point.

The curve fitting method was used to calculate underwater shock wave velocity and function approximation of the plotting point was done. The equation of Curve fitting method is as below. In this results, the shock wave velocity measured from experiment at the center of experimental device is shown in Fig. 7, Fig. 8. It showed that shock wave velocity is attenuated and it converges on sound velocity in water.

$$
y=A_{1}\left[1-\exp \left(-B_{1} t\right)\right]+A_{2}\left[1-\exp \left(-B_{2} t\right)\right]+A_{3}\left[1-\exp \left(-B_{3} t\right)\right]+c t
$$




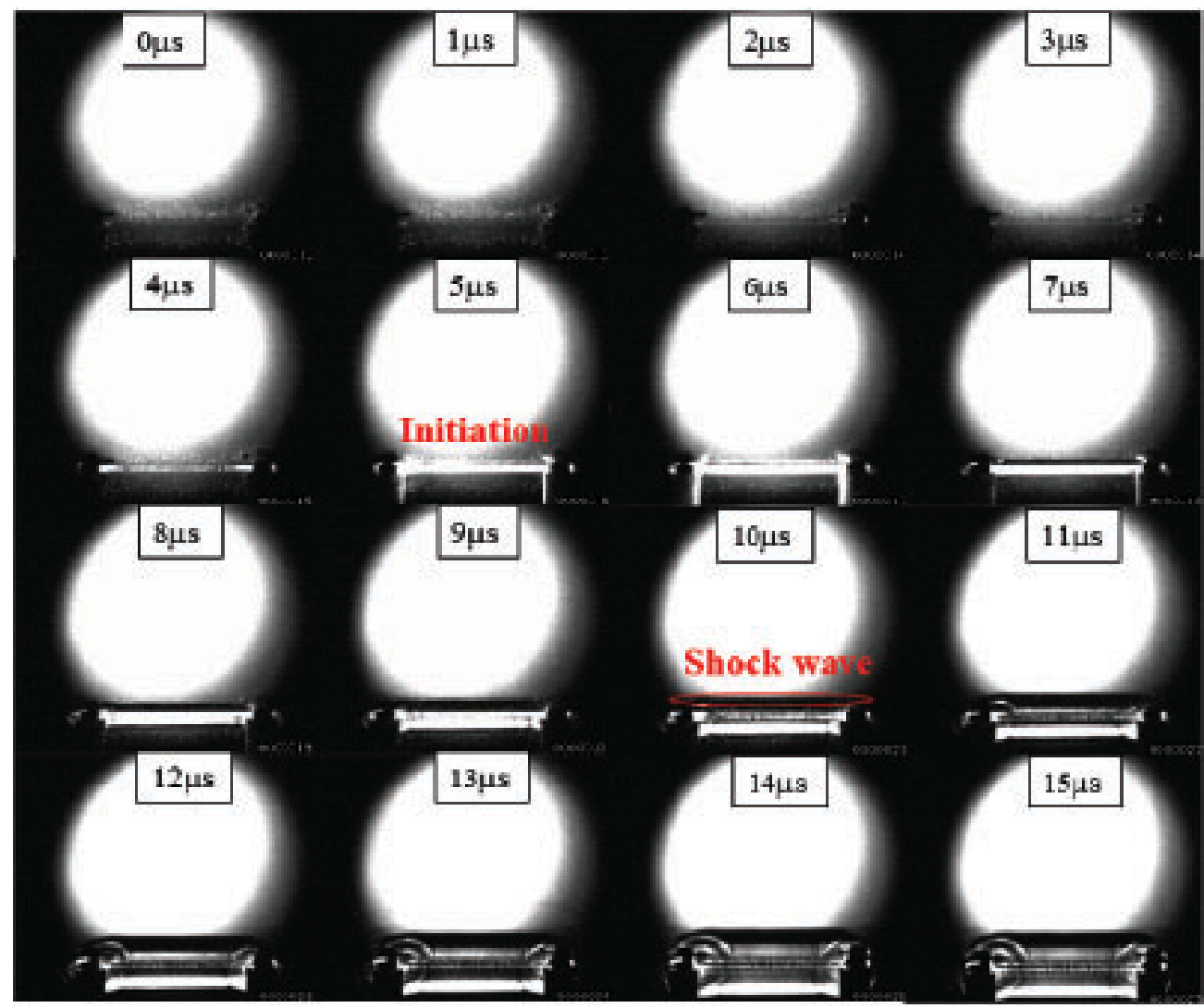

Figure 6 The flaming photograph using high-speed video camera HPV-1

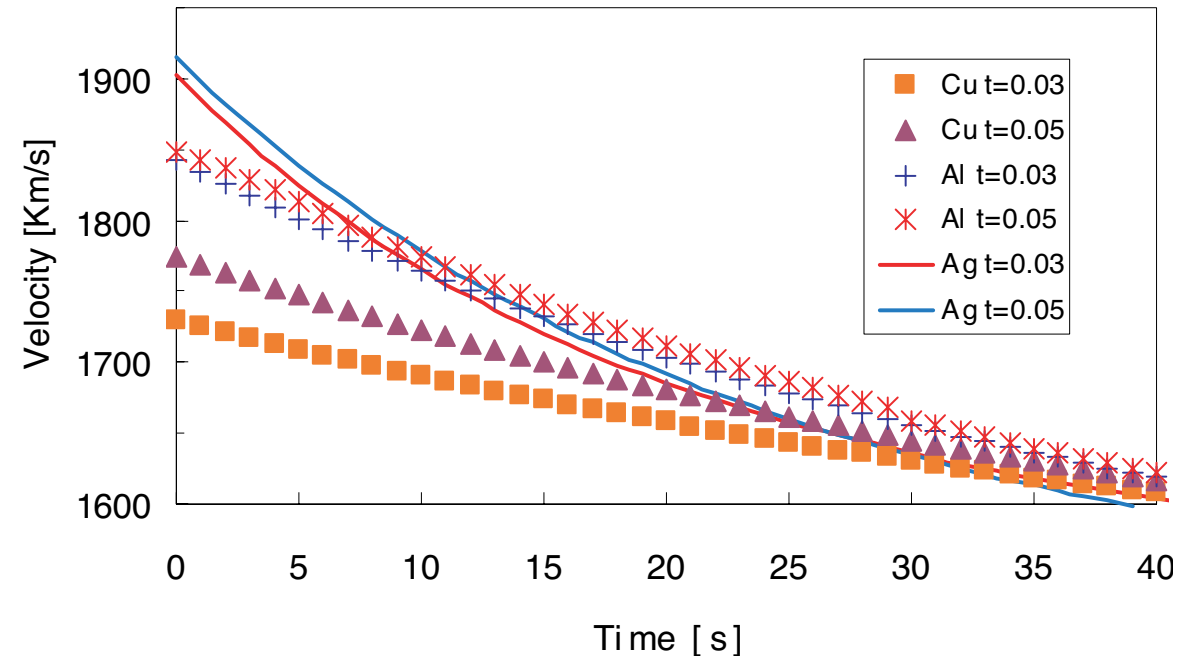

Figure 7 Velocity of underwater shock wave obtained experiment 


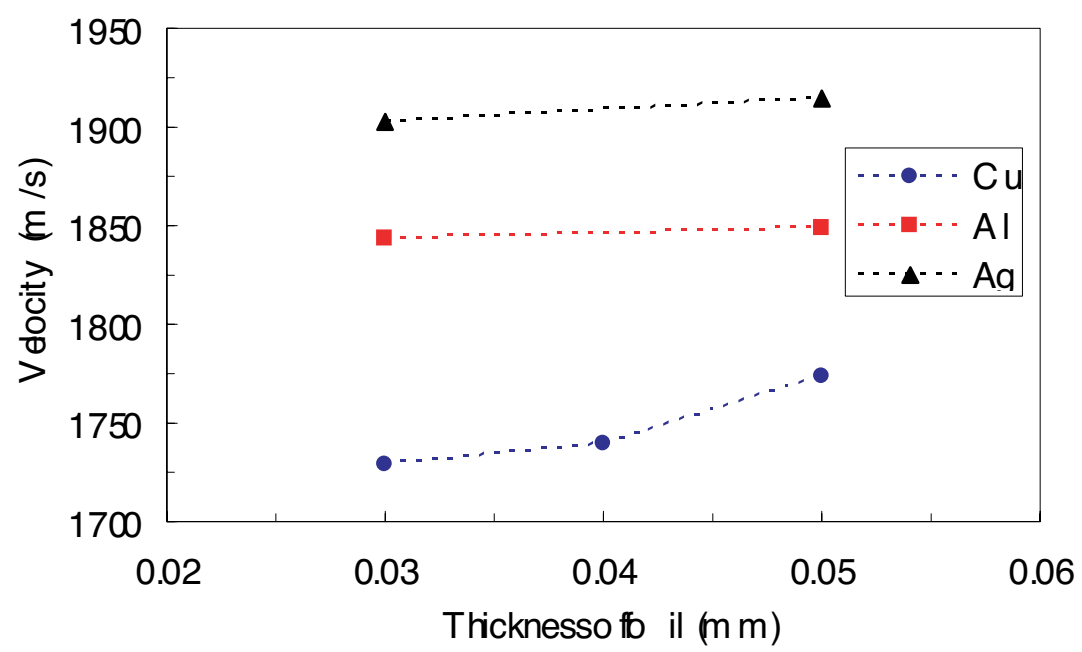

Figure 8 Maximum velocity in various thickness of foil

It is known between the shock wave velocity $U s$ and the particle velocity $u_{p}$ that the following relation will generally be realized. $\mathrm{C}_{0}$ and $\mathrm{s}$ are constants peculiar to a substance here, and $\mathrm{C}_{0}$ is in agreement with sound velocity. Moreover, when shock wave velocity and particle velocity are known, pressure $\mathrm{P}$ is given by the following equation.

$$
U_{s}=C_{0}+s u_{p}=\stackrel{\text { water }}{P=\rho U_{s} u^{p}} \quad \begin{aligned}
& r=1000 \mathrm{~kg} / \mathrm{m}^{3} \\
& C_{0}=1500 \mathrm{~m} / \mathrm{s} \\
& s=1.79
\end{aligned}
$$

Using above equation and value, shock wave pressure was calculated. This result is shown in Fig. 9, Fig. 10. Peak pressure is about 450MPa. Pressure as well as shock wave velocity is attenuating gradually.

\subsubsection{Current and voltage measurement}

Fig. 11, Fig. 12, Fig. 13 show the change in electric current and voltage for experiment, respectively. This parameter was measured using a Rogowski coil attached with cables and captured by digital oscilloscope. These figures showed that it took $5 \mu$ s from starting point to flow current to initiation point. Also, aluminum is different current form. And discharging time is very short. So, I think aluminum getting high power shock wave more than cupper in spite of low electric conductivity metal. Now, I am investigating whether there is a relation between current and shock wave velocity.

\subsection{NUMERICAL SIMULATION OF METAL FOIL EXPLOSION}

Fig. 14 shows comparison between experimental result and numerical analysis result. Also Fig. 15 shows the images clipped from the movie file of numerical analysis. This is a pressure distribution. Red zone is high pressure. It is confirmed that the pressure is gradually attenuating.

Numerical analysis using LS-DYNA provided comparatively good agreement with result from experiment. Maximum pressure is almost coincident with experimental value and numerical analysis. 


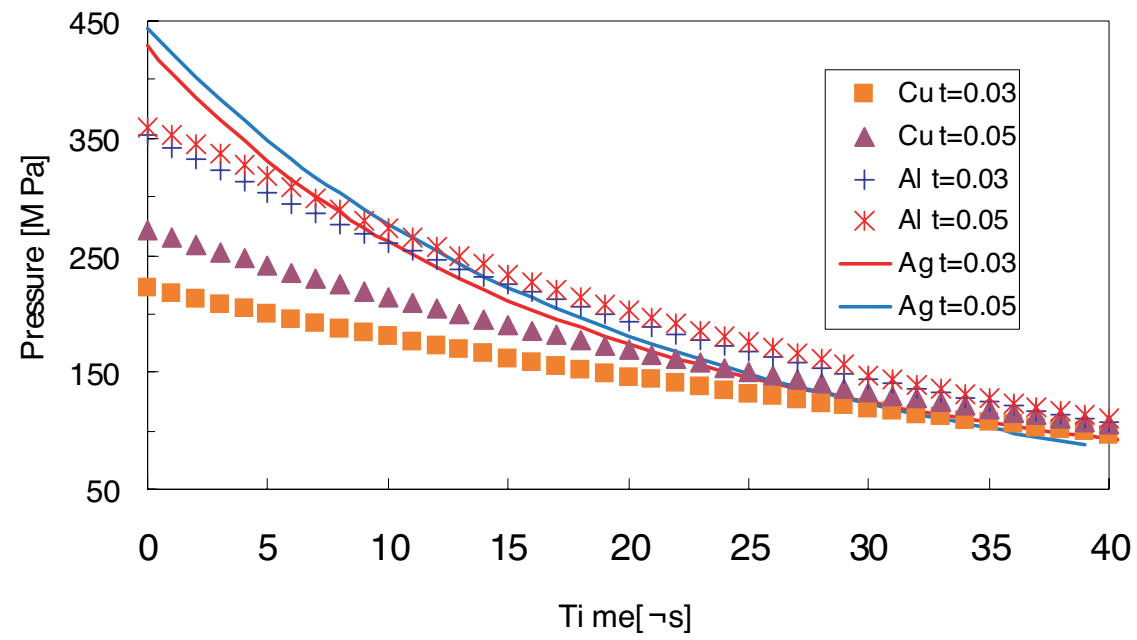

Figure 9 Pressure of underwater shock wave obtained experiment

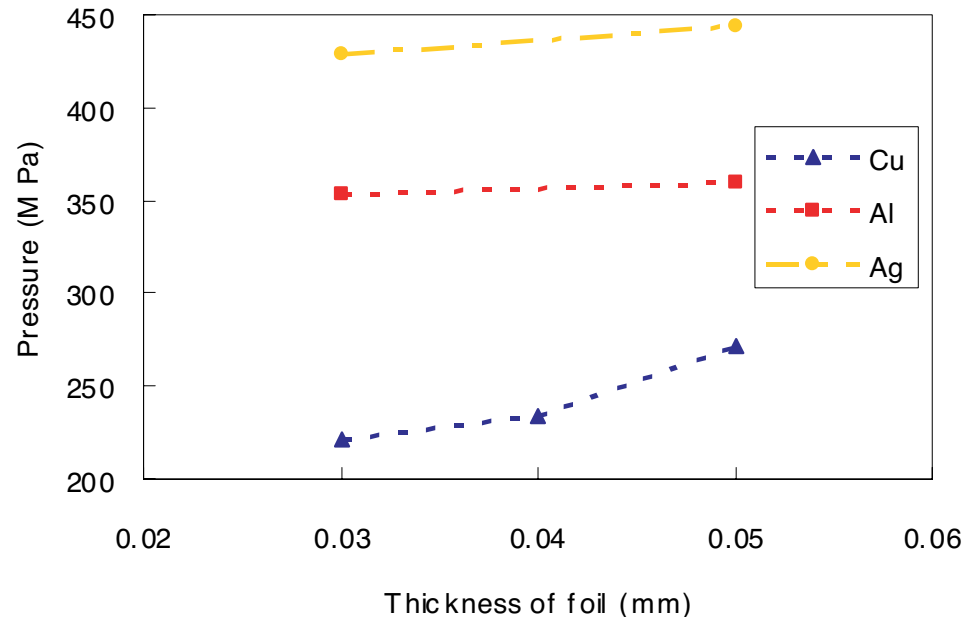

Figure 10 Maximum pressure in various thickness of foil

Table 3 Maximum pressure

Experimental value

Maximum pressure (MPa)

438.8

Numerical analysis 434.8

\subsection{NUMERICAL SIMULATION OF INITIATION SENSITIVITY}

We found out the following point in order to evaluate the adequacy of Lee and Tarver model using numerical simulation. 


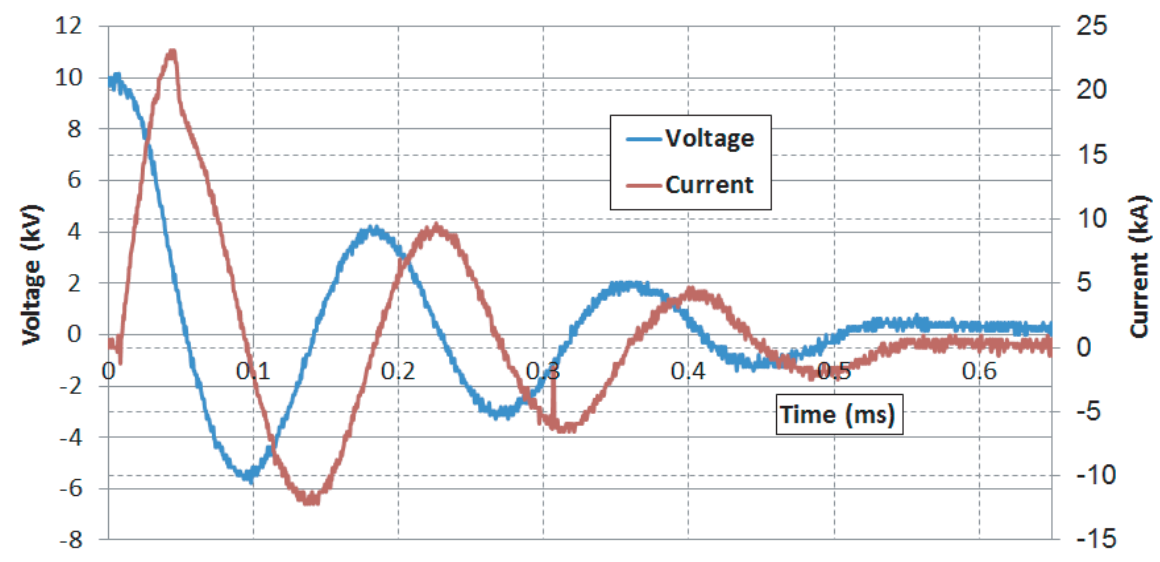

Figure 11 Current wave profile of experiment on cupper

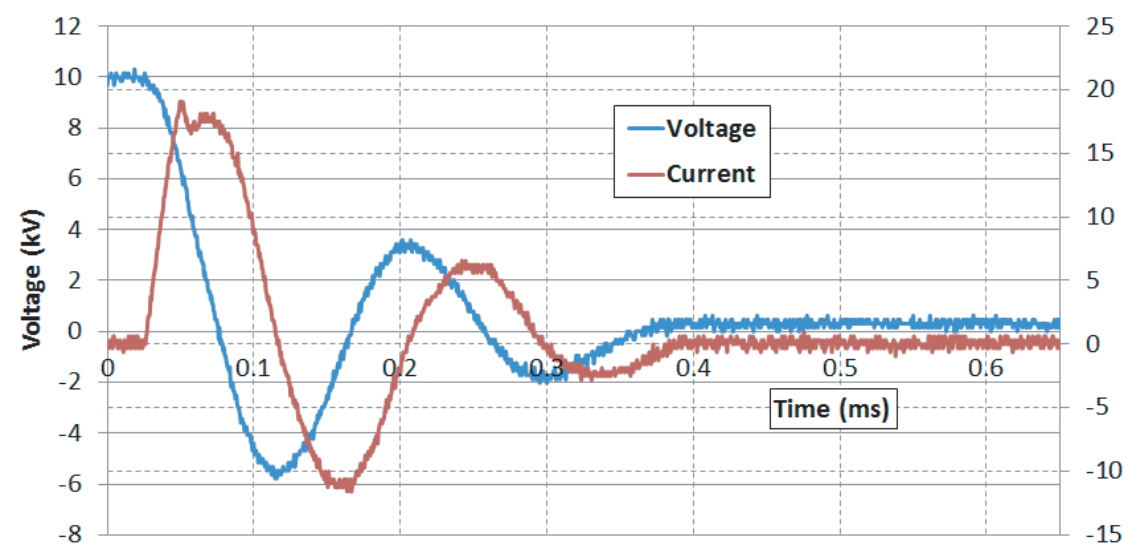

Figure 12 Current wave profile of experiment on aluminum

1. Evaluation of the explosion reaction rate of Comp. B

2. Attenuating shock wave through PMMA layer

3. Measurement of detonation pressure and detonation velocity of Comp. B

History on pressure contribution and peak pressure of shock wave are shown in Fig. 17, Fig. 18 respectively. Fig. 16 is in the case of the thickness of the PMMA $60 \mathrm{~mm}$. The case of the PMMA thickness of $40 \mathrm{~mm}, 50 \mathrm{~mm}$, as soon as shock wave entered, Comp. B was initiated. The case of the PMMA thickness of $60 \mathrm{~mm}$, after the shock wave entered, it initiated after a while. About this result, it is thought that the state before transferring to detonation is deflagration. And, transition to detonation from deflagration in heterogeneous solid explosive such a Comp. B is consisted to be accelerated the shock wave when exothermal reaction by hot spot occurred at shock wave behind. It is thought that that detonation phenomenon is not seen immediately after shock wave incidence has the low initiation power of shock wave, and it is because transition to detonation from deflagration took time. Here, 


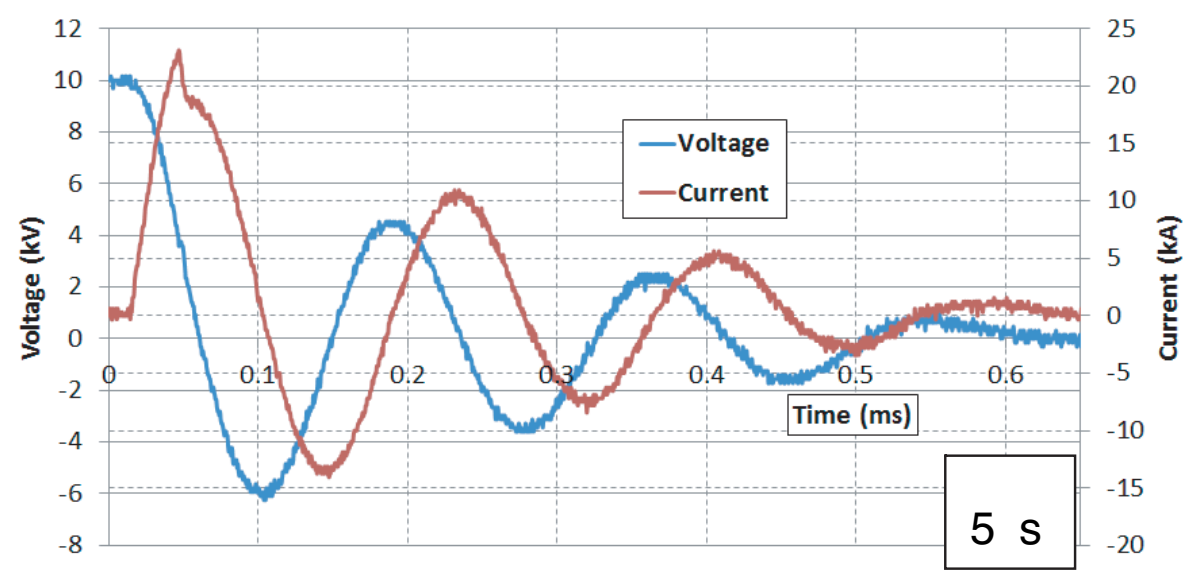

Figure 13 Current wave profile of experiment on silver

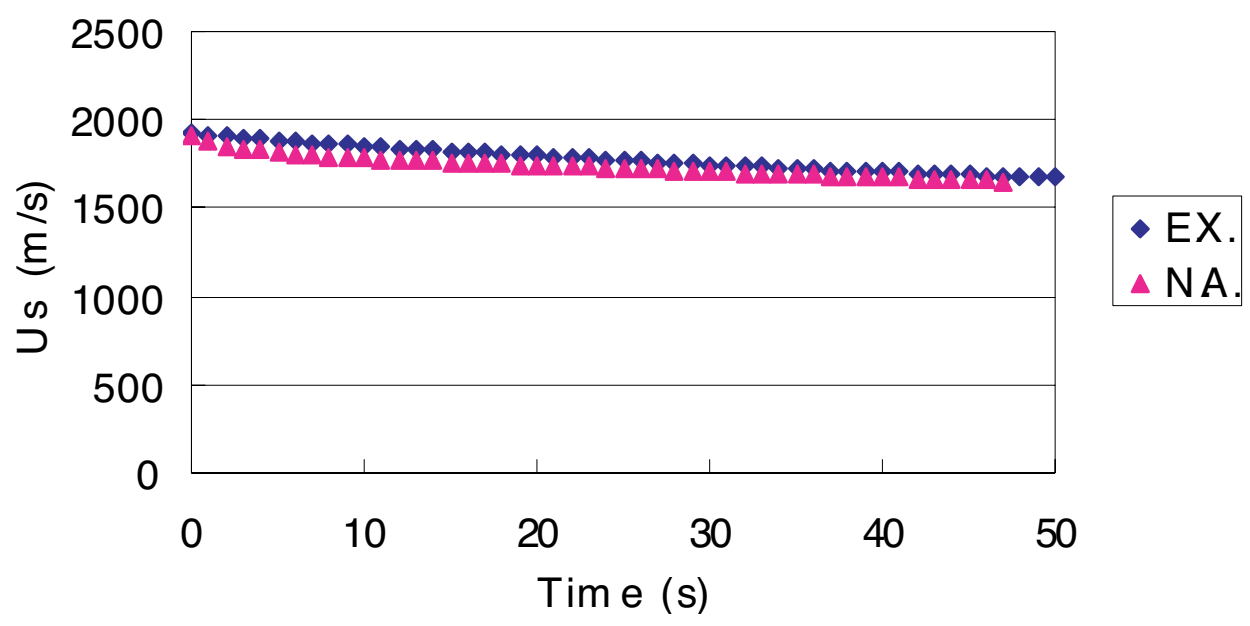

Figure 14 Fig. 14 Numerical simulation of shock wave velocity

it was $0.4 \mathrm{GPa}$ when the incidence wave pressure of Comp. B in the case of the PMMA thickness of $60 \mathrm{~mm}$ was measured. Detonation pressure and detonation velocity of Comp. B are shown in Fig. corresponding to a regulated value.

\section{CONCLUSION}

\subsection{METAL FOIL EXPLOSION}

- This result, initial velocity of shock wave is about $1900 \mathrm{~m} / \mathrm{s}$, then this velocity was attenuated and it finally converged sound velocity in water of $1500 \mathrm{~m} / \mathrm{s}$.

- The maximum velocity was obtained from argentine. It seems that argentine is most highest electric conductivity.

- Numerical analysis provided comparatively good agreement with result from experiment. 


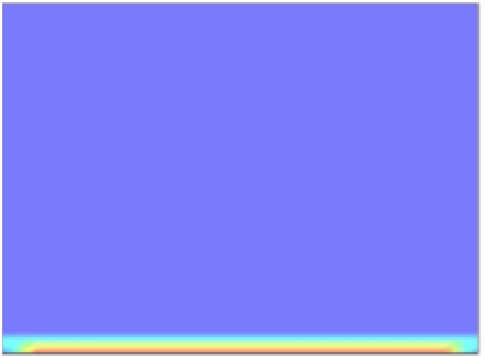

$0.45 \mu \mathrm{s}$

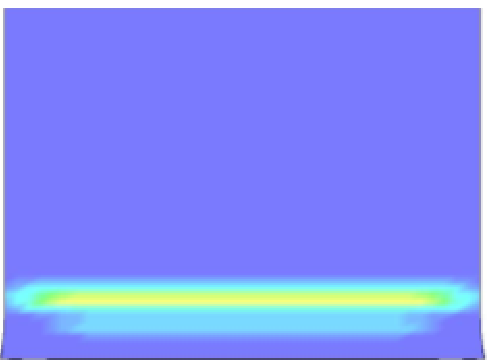

$2.0 \mu \mathrm{s}$

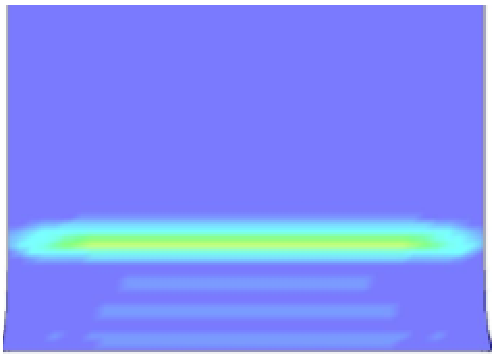

$3.3 \mu \mathrm{s}$

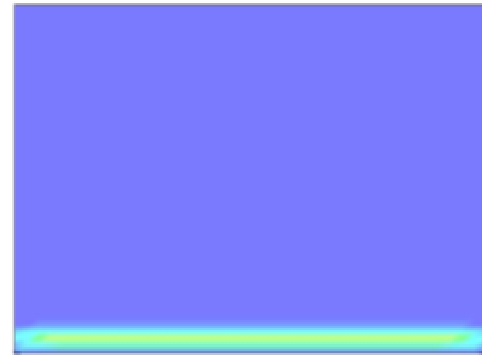

$0.65 \mu \mathrm{s}$

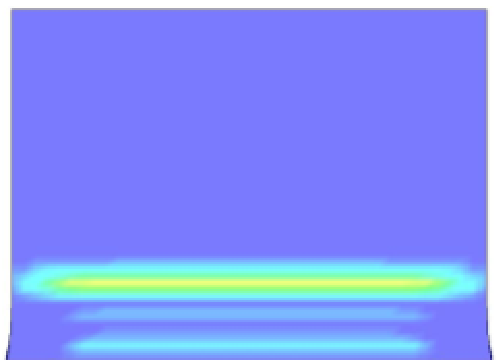

$2.5 \mu \mathrm{s}$

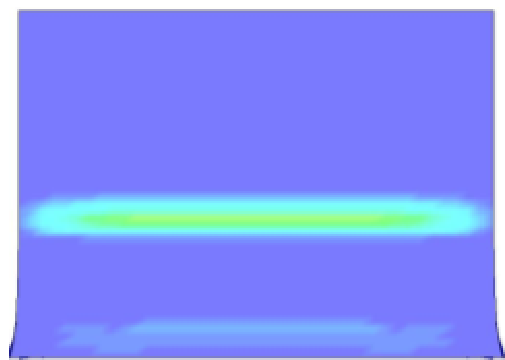

$4.2 \mu \mathrm{s}$
Fringe Levels

$4.500 \mathrm{e}-02 \times 10[\mathrm{GPa}]$

4.350e-02

4.200e-02

4.050e-02

3.900e-02

$3.750 \mathrm{e}-02$

$3.600 \mathrm{e}-02$

$3.450 \mathrm{e}-02$

3.300e-02

$3.000 \mathrm{e}-02$

2.850e-02

2.700e-02

$2.550 \mathrm{e}-02$

2. $400 \mathrm{e}-02$

$2.250 \mathrm{e}-02$

$2.100 \mathrm{e}-02$

$1.950 \mathrm{e}-02$

$1.800 \mathrm{e}-02$

$1.650 \mathrm{e}-02$

1.350e-02

$1.200 e-02$

$1.050 \mathrm{e}-02$

9.000e-03

$7.500 \mathrm{e}-03$

$6.000 \mathrm{e}-03$

4.500e- 03

$3.000 \mathrm{e}-03$

$1.500 \mathrm{e}-03$

$0.000 \mathrm{e}+00$

Figure 15 Pressure distribution

- For the future, I investigate whether there is a relation between current and shock wave velocity.

- I will make new experimental device to generate high pressure using reflect wave. Also, I'm thinking the experimental device using convergent wave.

\subsection{NUMERICAL SIMULATION OF INITIATION SENSITIVITY}

- It has been understood $12.5 \mathrm{GPa}$ initial incident pressure to PMMA, and to attenuate gradually afterwards.

- Detonation pressure and detonation velocity of Comp.B were corresponding to a regulated value.

- $\quad$ Comp.B initiated in the case of PMMA thickness $40 \mathrm{~mm}$ to $60 \mathrm{~mm}$.

- The case of PMMA thickness $60 \mathrm{~mm}$, the deflagration state was seen.

- In the future, I will experiment based on this numerical analysis result. 


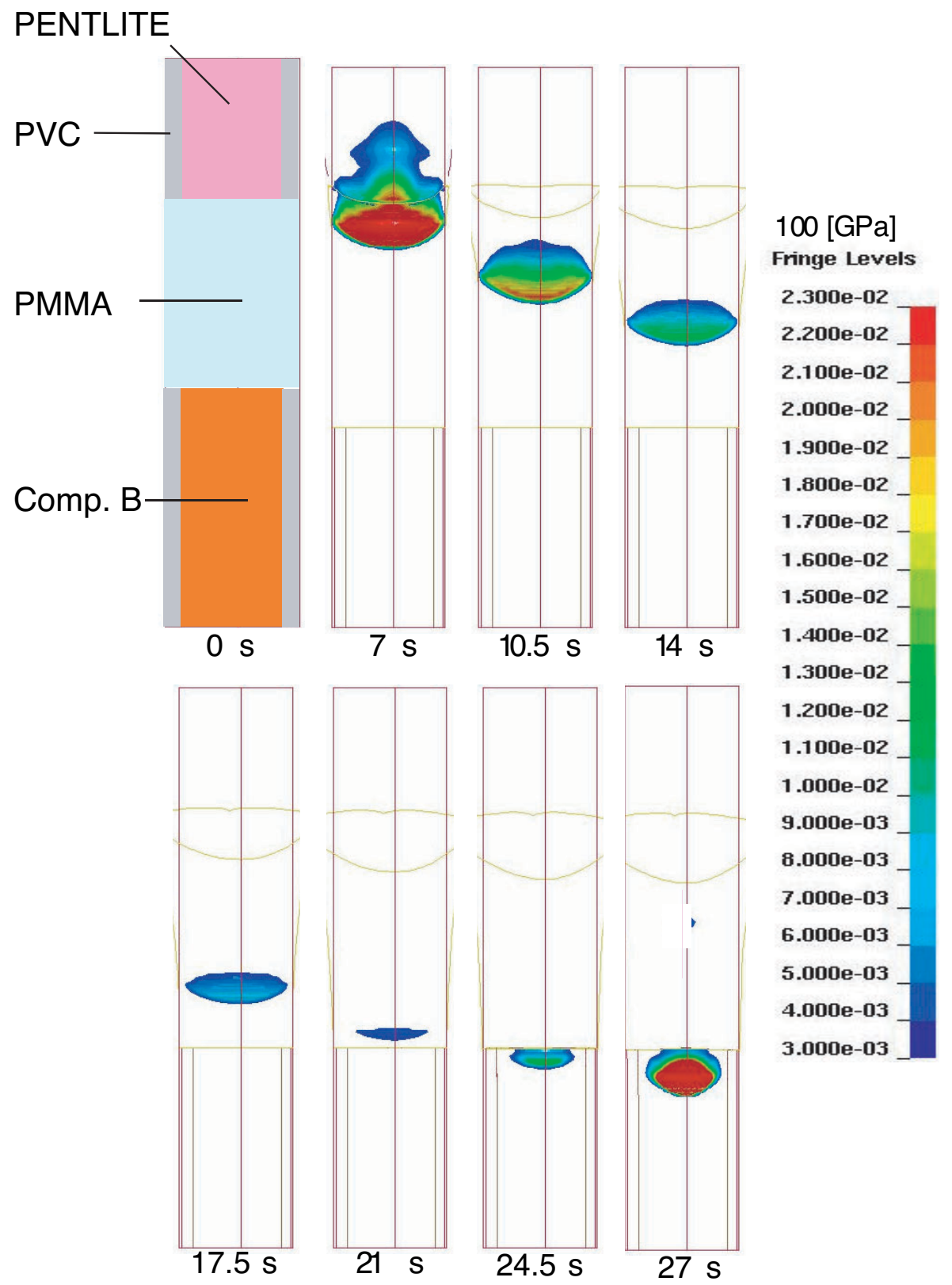

Figure 16 Pressure of shock wave propagating in PMMA 


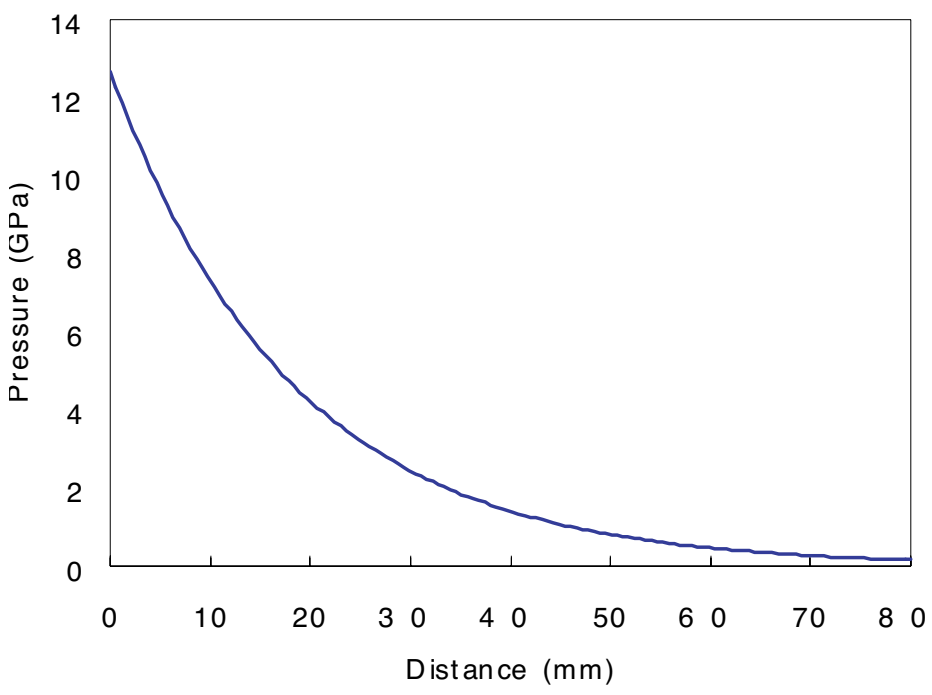

Figure 17 Pressure history of shock wave propagating in PMMA

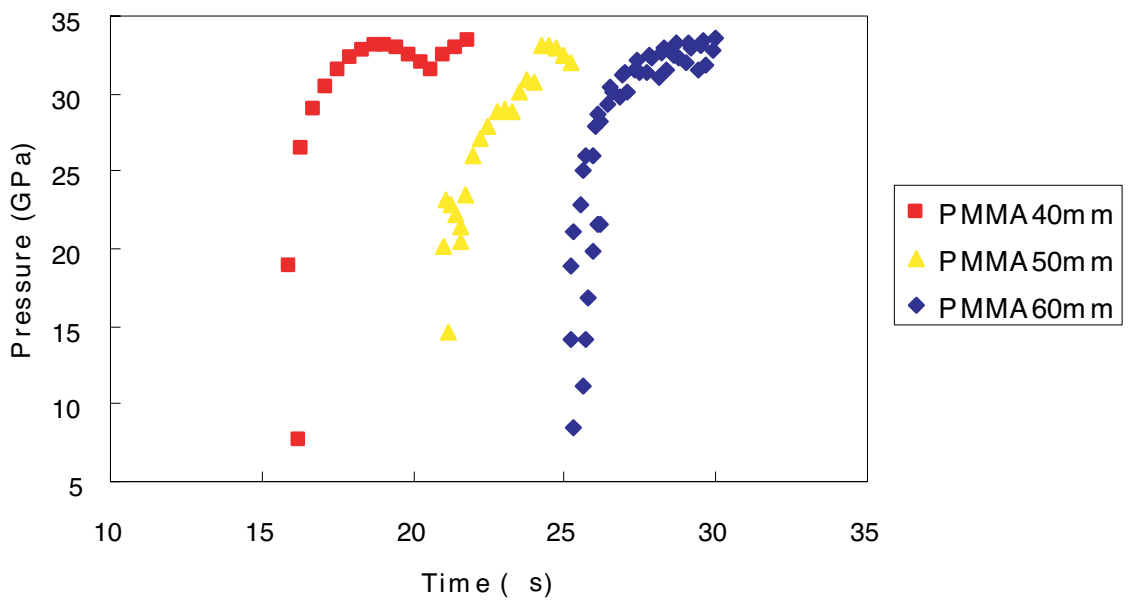

Figure 18 Pressure history of Comp. B

\section{REFERENCES}

[1] Tetsuyuki Hiroe, "Generation and application of planer detonation wave using wire explosion", Journal of the Industrial Explosives Society, Japan, vol.53 (4) P219-P226 (1992)

[2] S. P. Marsh, LASL Shock Hugoniot Data, University of California Press (1980)

[3] P. W. Cooper, "A new look at the run distance correlation and its relationship to other non-steady-state phenomena", Tenth International DETONATION Symposium, New Mexico, P690-695(1993)

[4] Shiro KUBOTA, "Numerical investigation on shock initiation of high explosive using Lee-Tarver model", Journal of the Explosives Society, vol. 62 (2) P57-63(2001)

[5] Masahiko Otsuka, "A study on initiation characteristics of metal wire by wire explosion", Fluids engineering conference 2003 ,Japan, P11 (2003) 
